NOTES

\title{
Moisture Characteristic and Structure of High Molecular Weight Sericin Film
}

\author{
Hajime MiYaKe, Hiroyuki Wakis AKA, Yoshitaka YAmashita, ${ }^{*}$ and Masanobu NAGURA* \\ North Eastern Industrial Research Center of Shiga Prefecture, 27-39 Mitsuyamotomachi, Nagahama 526-0024, Japan \\ ${ }^{*}$ Faculty of Textile Science and Technology, Shinshu University 3-15-1 Tokida, Ueda 386-8567, Japan
}

(Received April 14, 2003; Accepted June 24, 2003)

KEY WORDS Sericin / Film / High Molecular Weight / Hydrolysis / Cross-Link / Moisture Characteristic / Mechanical Properties / Structure /

Sericin, a silk protein, shows a high moistureretaining property and an ultraviolet ray absorbability, and has been applied for a textile processing of medicines and a cosmetic additives. ${ }^{1}$ It is clarified by recent studies that sericin has many physiological effects, such as an anti-oxidative effect, a cancer prevention and a dermatitis improvement, etc. ${ }^{2-6}$ Furthermore, the practical physical properties of the sericin make it a promising material for the field of medical supplies.

Sericin adheres firmly with fibroin protein. Since it has high molecular weight, most of sericin is insoluble in water at room temperature. ${ }^{7}$ Industrially, sericin can be extracted by the scouring of silk fabric and silk yarn in an alkaline solution under high temperature and pressure. The molecular weight of the sericin obtained is greatly lowered by the hydrolysis, and then the water solubility increases. Therefore, the material, such as a film or membrane, composed only the low molecular weight sericin is lacking in the practicability, because of the material simply dissolves in the water. One of the authors examined the chemical cross-linking using dimethylolurea (DMU), and membranes obtained showed water resistance. ${ }^{8}$ However, to utilize for medical supplies, it is desirable to unused the other substance, such as cross-linking agent because of toxicity. In addition, Katoh suggested that the physiological effects of sericin depend on the molecular weight?

Recently, we developed a new process to efficiently obtain the sericin, which maintain high molecular weight. ${ }^{10,11}$ Furthermore, we found that the film prepared by this sericin showed water resistance and large mechanical properties. In order to apply this material to the medical field, it is necessary to evaluate the moisture characteristic or the structure.

In this paper, it is reported that the high molecular weight sericin film compared with the cross-linking sericin film on moisture characteristic and structure.

\section{EXPERIMENTAL}

\section{Molecular Weight}

The molecular weight of the sericin was determined by gel permeation chromatography (GPC) using a D7000 (Hitachi Seisakusho Co., Ltd.). The instrument conditions were as follows: elution solvent, $0.05 \mathrm{~mol}$ phosphoric acid buffer $+0.3 \mathrm{~mol} \mathrm{NaCl}$; gel column, Shodex Asahipak 520HQ; temperature, $35^{\circ} \mathrm{C}$; flow rate, $0.6 \mathrm{~mL} \mathrm{~min}^{-1}$. MW-Marker (Oriental Yeast Co., Ltd.) was used as calibrating standard.

\section{Materials}

A high molecular weight sericin powder was kindly supplied by Kashiro-Sangyo Co., Ltd. (Shiga, Japan.) and used without purification. The weight average molecular was $3.88 \times 10^{5}$.

\section{Preparation of High Molecular Weight Sericin Film}

The high molecular weight sericin powder was dissolved in water using an autoclave $\left(105^{\circ} \mathrm{C}, 3 \mathrm{~min}\right)$. A sericin aqueous solution of $2 \mathrm{wt} \%$ was cast on a Teflon petri dish and then dried at room temperature.

\section{Preparation of Hydrolyzed and Cross-Linked Sericin Films}

The high molecular weight sericin powder was hydrolyzed in a $0.2 \mathrm{wt} \% \mathrm{Na}_{2} \mathrm{CO}_{3}$ aqueous solution using an autoclave $\left(110^{\circ} \mathrm{C}, 5 \mathrm{~min}\right)$, neutralized with $\mathrm{HCl}$. The weight average molecular of hydrolyzed sericin was $0.23 \times 10^{5}$. The aqueous solution obtained was mixed with dimethylolurea (DMU) as a cross-linking agent at a mole ratio of 0.5 for the sericin and agitated at $85^{\circ} \mathrm{C}$ for $1 \mathrm{~h}$, cast on a Teflon laboratory dish and dried at room temperature. The cross-linked sericin film obtained was cured at $130^{\circ} \mathrm{C}$ for $10 \mathrm{~min}$ and dried after washing in water. 
Fourier Transform Infrared Spectrophotometer (FT-IR)

Infrared spectra were obtained at a wave-number region of $1400-1800 \mathrm{~cm}^{-1}$, resolution of $0.5 \mathrm{~cm}^{-1}$ and the scan frequency of 200 times with a Fourier Transform Infrared Spectrophotometer SpectrumOne (PerkinElmer Instruments).

\section{X-Ray Diffraction}

$\mathrm{X}$-Ray diffraction intensity curves were obtained at a scanning rate of $1^{\circ} \mathrm{min}^{-1}$ for $2 \theta$ from 5 to $50^{\circ}$ with a diffractometer Rint 2000 (Rigaku Denki Co., Ltd.) using $\mathrm{Cu}-K \alpha$ radiation. The powder sample which was fractured by film samples was used for the measurement.

\section{Thermogravimetry (TG)}

TG was measured using TG-DTA TAS-2000 (Rigaku Denki Co., Ltd.). Measurements were taken over a temperature range of 80 to $350^{\circ} \mathrm{C}$ in the nitrogen atmosphere at a rate of $10^{\circ} \mathrm{C} \mathrm{min}^{-1}$.

\section{Tensile Properties}

Tensile properties were measured with an Instron tensile tester (Instron Japan Co., Ltd.). The tensile speed was $20 \mathrm{~mm} \mathrm{~min}^{-1}$. The samples were prepared by keeping the sample under the standard condition $\left(23{ }^{\circ} \mathrm{C}\right.$, RH $\left.55 \%\right)$ for $24 \mathrm{~h}$. Young's modulus were calculated from the initial slope of the stress-strain curves.

\section{Elution Protein Composition}

The sericin films were dipped into water at various temperature for $8 \mathrm{~h}$. The elution protein composition from sericin films were determined by Bradford method using ultraviolet spectrophotometer UV-1600PC (Shimadzu seisakusho Co., Ltd.). Bovine serum albumin (BSA) was used as calibrating standard.

\section{Swelling Ratio and Water Regain}

The swelling ratio and the water regain were calculated by eqs 1 and 2, respectively,

$$
\text { Swelling ratio }(\%)=V_{\mathrm{w}} / V_{\mathrm{d}} \times 100
$$

where $V_{\mathrm{w}}$ is the volume of the swollen sample obtained by dipping into water at $25^{\circ} \mathrm{C}$ for $8 \mathrm{~h}$ and $V_{\mathrm{d}}$ is the volume of the dried sample obtained by vacuum drying at $30^{\circ} \mathrm{C}$ for $24 \mathrm{~h}$.

$$
\text { Water regain }(\%)=\left(W_{\mathrm{w}} / W_{\mathrm{d}}-1\right) \times 100
$$

where $W_{\mathrm{w}}$ is the weight of the water-absorbed sample obtained by dipping into water at $25^{\circ} \mathrm{C}$ for $8 \mathrm{~h}$ and $W_{\mathrm{d}}$ is the weight of the dried sample obtained by vacuum drying at $30^{\circ} \mathrm{C}$ for $24 \mathrm{~h}$.

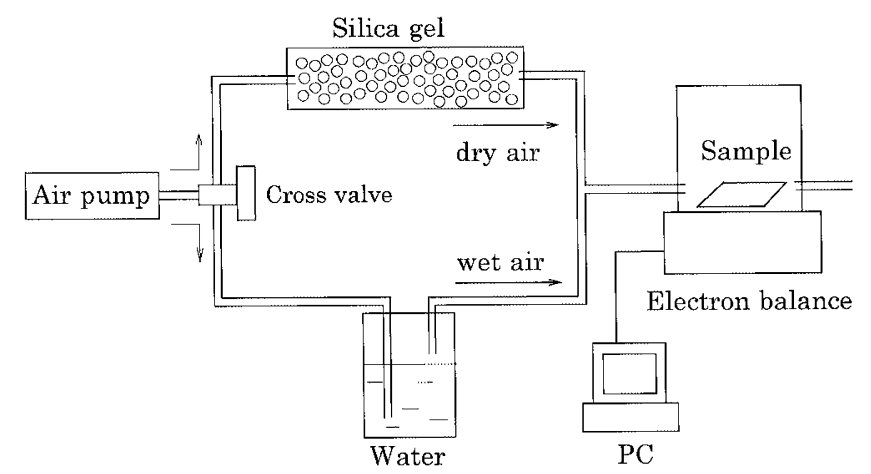

Figure 1. Apparatus for the measurement of hygroscopicity and dehygroscopicity.

\section{Moisture Regain}

Moisture regain in the films was calculated by eq 3 ,

$$
\text { Moisture regain }(\%)=\left(W_{\mathrm{w}} / W_{\mathrm{d}}-1\right) \times 100
$$

where $W_{\mathrm{w}}$ is the weight of the moisture-absorbed sample obtained by keeping the sample in a incubatorhumidistat at $23^{\circ} \mathrm{C}$ for $24 \mathrm{~h}$, and $W_{\mathrm{d}}$ is the weight of a dried sample obtained by vacuum drying at $30^{\circ} \mathrm{C}$ for $24 \mathrm{~h}$.

\section{Hygroscopicity and Dehygroscopicity}

Hygroscopicity and dehygroscopicity were measured with the apparatus which was showed in Figure 1. The weight change of the sample under the dry or wet conditions were plotted 3 min interval.

\section{RESULTS AND DISCUSSION}

\section{Structures of High Molecular Weight Sericin Film}

Figure 2 shows FT-IR spectra of high molecular weight sericin (high- $M_{\mathrm{w}}$ sericin), hydrolyzed sericin and cross-linked sericin films. In the high- $M_{\mathrm{w}}$ sericin film, there are a peak at $1624 \mathrm{~cm}^{-1}$ with a shoulder on the high wave-numbers side $\left(1645 \mathrm{~cm}^{-1}\right)$ and a peak at $1514 \mathrm{~cm}^{-1}$. Since these peaks in FT-IR spectra are related to the amide $\mathbf{I}$ and the amide II absorption band respectively, which are due to a peptide linkage forming a $\beta$-sheet, ${ }^{12,13}$ sericin molecules in the high- $M_{\mathrm{w}}$ sericin film mainly form a $\beta$-sheet. Here, the shoulder peak at $1645 \mathrm{~cm}^{-1}$ obviously transformed into a new peak at the hydrolyzed and the cross-linked sericin films. Further a new shoulder peak appeared at $1527 \mathrm{~cm}^{-1}$. These peaks are related to the amide $\mathbf{I}$ and the amide II absorption band due to a peptide linkage forming random coil of peptide, respectively. ${ }^{12,13}$ These results indicate that the random coil in the hydrolyzed and the crosslinked sericin films increases by the destruction of a $\beta$-sheet structure due to the alkaline hydrolysis or the cross-linking.

Figure 3 shows X-ray diffraction intensity curve of 


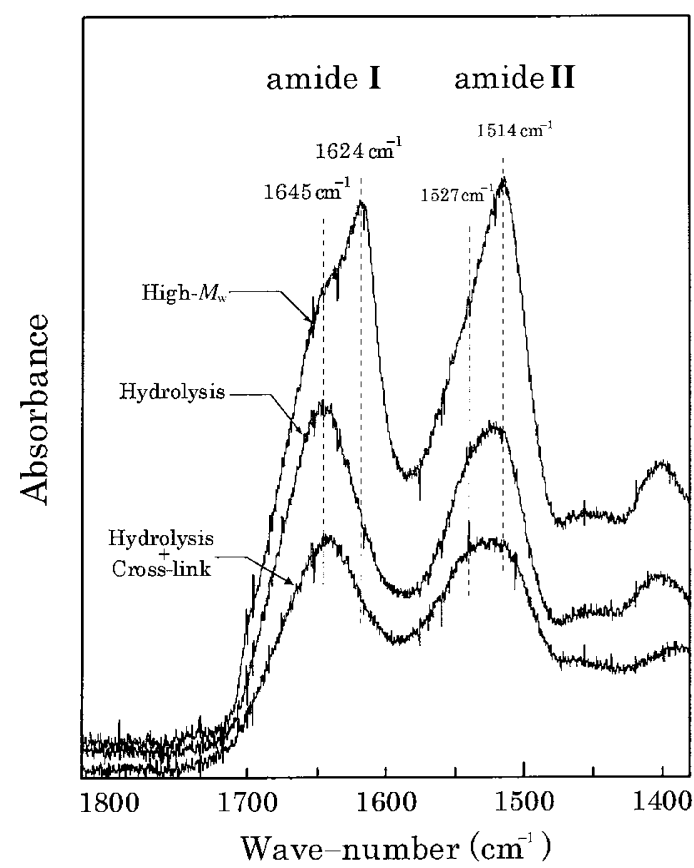

Figure 2. FT-IR spectra of sericin films.

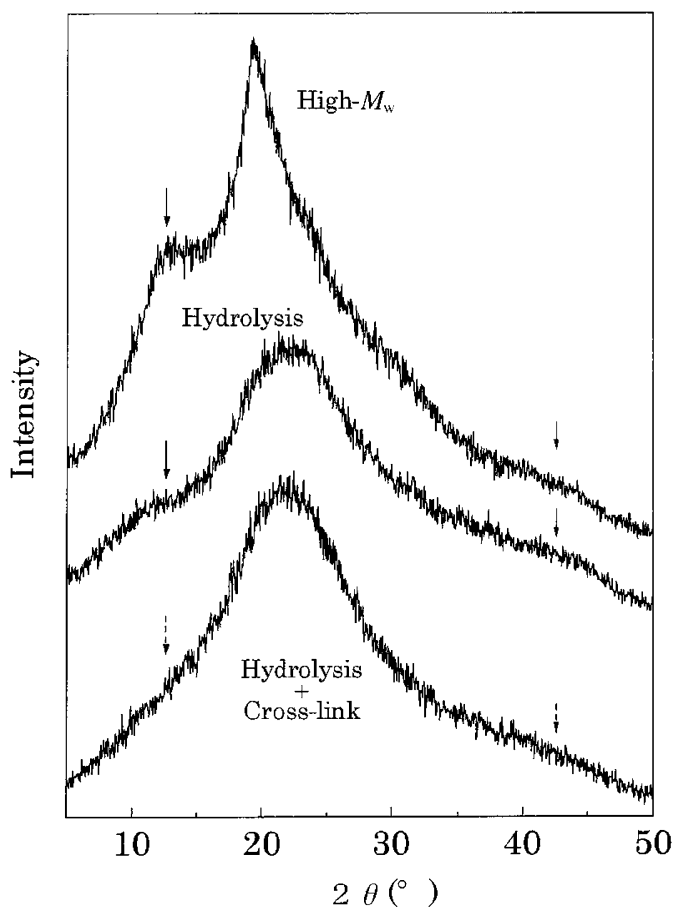

Figure 3. Wide angle X-ray diffraction patterns of sericin films.

each films. Komatsu shows ${ }^{7}$ that the diffraction peak angles calculated from crystal spacing of the hot water extraction sericin were at $2 \theta=12.1^{\circ}, 19.6^{\circ}, 21.2^{\circ}$, $26.9^{\circ}$, and $44.6^{\circ}$. In the high $-M_{\mathrm{w}}$ sericin film, there is a diffraction peak at near $2 \theta=20^{\circ}$, and a shoulder peak at near $2 \theta=12^{\circ}, 28^{\circ}$, and $43^{\circ}$. The observed diffraction angles agreed with calculated ones, indicating that the high- $M_{\mathrm{w}}$ sericin film maintains original crystal structure. On the other hand, the peak at near $2 \theta=20^{\circ}$ transformed into a broad peak while the shoulder peak

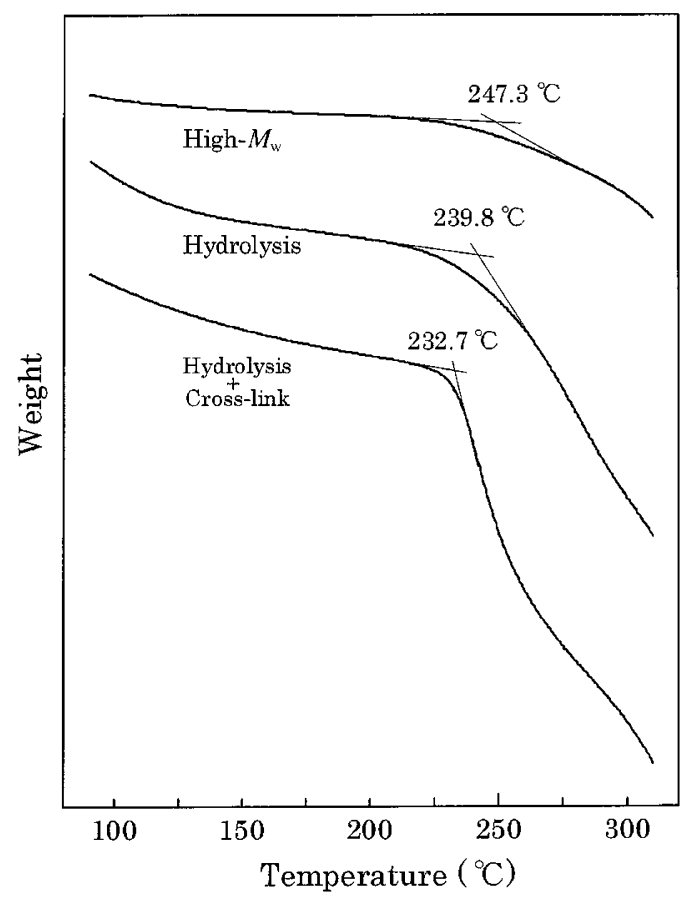

Figure 4. TG curves of sericin films.

at near $2 \theta=12^{\circ}$ decreased in the hydrolyzed sericin film. Furthermore, only a broad peak is observed in the cross-linked one. This peak will be an amorphous harrow, since the absorption band due to the random coil was observed in FT-IR spectra, as mentioned above. These results support the consideration from the results of FT-IR, namely crystal region in the sericin was decreased by alkaline hydrolysis or cross-linking. Here, the cross-linking gives water resistance, but it promotes the decrystallization. It is assumed that the promotion of decrystallization by cross-linking is attributed to the heating for the agitation with $\mathrm{DMU}\left(85^{\circ} \mathrm{C}\right.$ for $\left.1 \mathrm{~h}\right)$ or the curing $\left(130^{\circ} \mathrm{C}\right.$ for $\left.10 \mathrm{~min}\right)$, and the extraction of the excess DMU.

Figure 4 shows TG curve of each sericin films. In the high- $M_{\mathrm{w}}$ sericin film, a weight loss due to the decomposition occurred from near $250^{\circ} \mathrm{C}$, and that of the hydrolyzed and the cross-linked one gently occurred from near $240^{\circ} \mathrm{C}$ and $230^{\circ} \mathrm{C}$, respectively. The crystal region, which shows a high heat-resistance is more abounding in the high- $M_{\mathrm{w}}$ sericin film. In addition, a number of molecular chain ends are lower than that of hydrolyzed or the cross-linked sericin films, resulting the disturbance of the molecular motion. The higher decomposition temperature at the high- $M_{\mathrm{w}}$ sericin film was caused by these structures. Generally, the decomposition temperature in TG curve shows high temperature side by cross-linking. However, the decomposition temperature of cross-linked sericin film is lower than that of hydrolyzed one at about $7^{\circ} \mathrm{C}$. The decomposition start temperature of DMU was approximate with 
Table I. Tensile properties of sericin films

\begin{tabular}{lcc}
\hline & High- $M_{\mathrm{w}}$ & Cross-link \\
\hline Stress/MPa & 65.1 & 42.8 \\
Strain/\% & 2.1 & 3.7 \\
Young's modulus/MPa & 4060 & 1670 \\
\hline
\end{tabular}

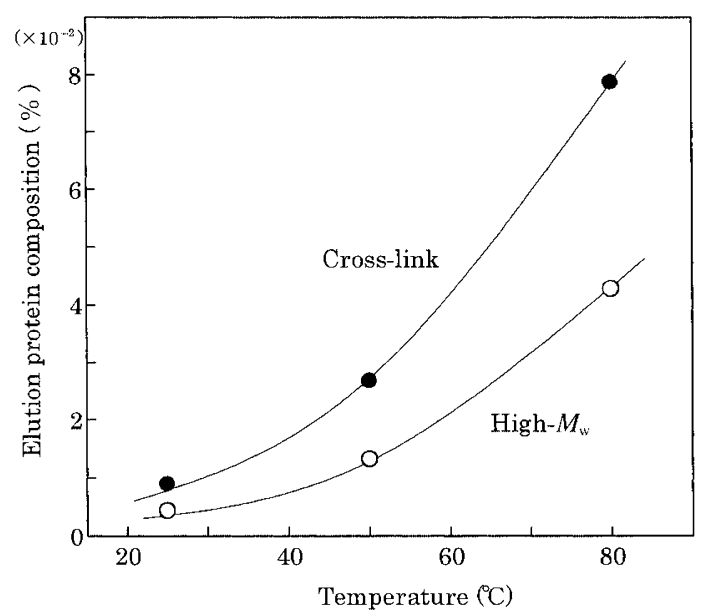

Figure 5. Dependence of elution protein content from sericin film on water temperature.

Table II. Water regain and swelling ratio of sericin films dipping into water

\begin{tabular}{lcc}
\hline & High- $M_{\mathrm{w}}$ & Cross-link \\
\hline Water regain/\% & 166.7 & 193.3 \\
Swelling ratio/\% & 122 & 180 \\
\hline
\end{tabular}

the decomposition temperature of hydrolyzed sericin (about $230^{\circ} \mathrm{C}$ ). Thus, the cross-linked sericin started of decomposition simultaneously with the collapse of cross-linking at near temperature. Furthermore, the crystal region of the cross-linked sericin is lower than that of hydrolyzed one, as mentioned above, resulting the decomposition temperature in TG curve shows lower than that of hydrolyzed one.

Tensile properties at standard condition $\left(23^{\circ} \mathrm{C}, \mathrm{RH}\right.$ $55 \%)$ of high- $M_{\mathrm{w}}$ and cross-linked sericin films are shown in Table I. Tensile stress and Young's modulus of the high- $M_{\mathrm{w}}$ sericin film are larger than that of the cross-linked one. This results support the assumption as that the crystal region is more abounding.

\section{Moisture Characteristic of High Molecular Weight Sericin Film}

Figure 5 shows that the elution protein composition from the specimens to various temperature water, and Table II shows that the water regain and swelling ratio when the films were dipped into water at $25^{\circ} \mathrm{C}$ for $8 \mathrm{~h}$, respectively. A trace amount of the elution protein was observed on cross-linked sericin film. There is non cross-linked sericin molecule with low molecular weight in the cross-linked sericin film, and this

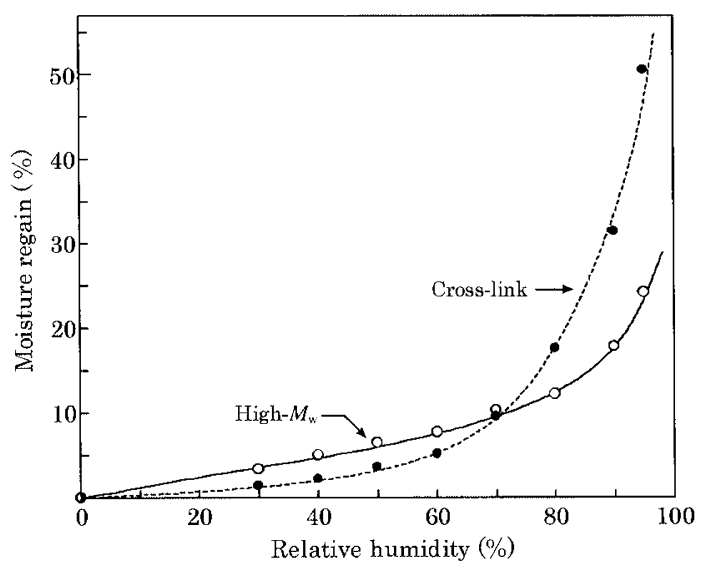

Figure 6. Isothermal sorption diagrams of sericin films.

can cause protein (i.e., sericin) elution. Here, dipping into water of the cross-linked sericin film resulted in large swelling, as shown in Table II. On the other hand, the elution protein composition of the high- $M_{\mathrm{w}}$ sericin film is lower than that of the cross-linked one. Furthermore, the water regain and the swelling rate are also lower. The high- $M_{\mathrm{w}}$ sericin film has many crystal region (i.e., $\beta$-sheet forming) with large intermolecular force, and water mainly entered into the amorphous region. Therefore the water regain and the swelling rate are lower than that of cross-linked sericin with many amorphous region.

Figure 6 shows that the isothermal sorption diagrams of both films. The diagram shows BET-type curve, in which case the adsorption shows the multilayer adsorption under the high humidity condition. ${ }^{14,15}$ For the relative humidity of below $70 \%$, moisture regain of cross-linked sericin film is lower than that of high- $M_{\mathrm{w}}$ one. However, the moisture regain rapidly increases for the relative humidity of above approximately $60 \%$, while the high- $M_{\mathrm{w}}$ one rapidly increases of above approximately $80 \%$, consequently moisture regain was reversed at the $70 \%$ humidity. Sericin has a large number of hydrophilic group (i.e., $-\mathrm{OH},-\mathrm{NH}$, and $-\mathrm{COOH}$ ). These groups are the important factors regulating the monolayer adsorption ability under the low relative humidity. It is assumed that the lower moisture regain of cross-linked sericin film observed in the low relative humidity is attributed to the decrease of the hydrophilic group due to the cross-linking with DMU. In the case of multilayer adsorption under the high relative humidity, the moisture adsorption accompanied with large swelling of the film, and the space for the physical adsorption of the moisture enlarges, resulting the higher hygroscopicity is shown. Figure 7 shows that the aspect of the hygroscopicity and dehygroscopicity of both films. At the time of the dehygroscopicity, it was found that the high- $M_{\mathrm{w}}$ sericin film take longer time to equilibrium of the moisture regain, in spite of the moisture 


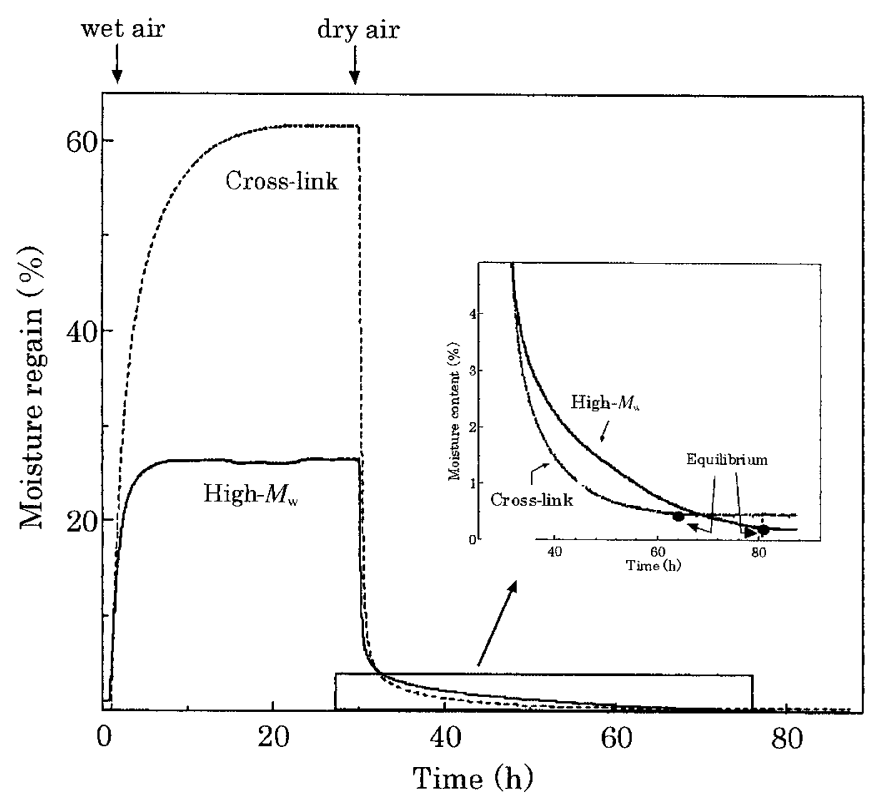

Figure 7. Aspect of the hygroscopicity and dehygroscopicity of sericin films.

regain under the wet condition was smaller. This result indicates that the fraction of the monolayer adsorption (i.e., chemical adsorption) which shows large adsorption force ${ }^{15}$ of high- $M_{\mathrm{w}}$ sericin film is higher than that of the cross-linked one. While the fraction of the multilayer adsorption (i.e., physical adsorption) which shows small adsorption force ${ }^{15}$ is lower than that of the crosslinked one. Because of the moisture regain under the wet condition was smaller. These results support the consideration from the results of isothermal sorption diagrams

Acknowledgment. The authors thank Kashiro-
Sangyo Co., Ltd. for supplying sericin powder. This work was supported by a Grant-in-Aid for Science Research (No. C(2)1450814) from the Ministry of Education, Culture, Sports, Science and Technology.

\section{REFERENCES}

1. M. Nomura and H. Yamada, Sen-i Gakkaishi, 48, 305 (1992).

2. N. Katoh, S. Satoh, A. Yamanaka, H. Yamada, N. Fuwa, and M. Nomura, Biosci., Biotechnol., Biochem., 62, 145 (1998).

3. N. Katoh, A. Shoji, and H. Yamada, Bio Industry, 15, 15 (1998).

4. A. Yamazaki, N. Nakamura, H. Kurioka, and K. Komatsu, J. Seric. Sci. Jpn., 68, 167 (1999).

5. N. Katoh and M. Sasaki, Skin Research, 41, 481 (1999).

6. N. Katoh and M. Sasaki, Fragrance J., 4, 28 (2000).

7. K. Komatsu, in "Zoku Kenshi no Kohzo", N. Hojyo, Ed., Shinshu University, Nagano, 1980, p 379.

8. M. Nagura, R. Onishi, Y. Gotoh, and Y. Ohkoshi, J. Insect Biotechnol. Sericol., 70, 149 (2001).

9. N. Katoh, presented at 54th Silk Summer Seminar, Okaya, July 26-27, 2001.

10. H. Miyake, S. Otu, and H. Wakisaka, Jpn. Patent 265498 (Sep. 18, 2002).

11. H. Miyake, S. Otu, and H. Wakisaka, Jpn. Patent 265499 (Sep. 18, 2002).

12. K. Nakanishi, P. H. Solomon, and N. Furutachi, in "Infrared Absorption Spectroscopy”, Nankodo, Tokyo, 1993, p 45.

13. H. Miyake, H. Wakisaka, and M. Nagura, J. Insect Biotechnol. Sericol., 71, 85 (2002).

14. H. Nanjou, in "Zoiryou to Suibun Hand Book", H. Miyabe, Ed., Kyoritsu Shuppan, Tokyo, 1968, p 15.

15. T. Takeuchi, in "Kyuchaku no Kagaku", Sangyo Tosho, Tokyo, 1995, p 54. 